\title{
The future of sports delivery in Australia NBN multicast, IPTV and the role of the ISPS
}

\author{
Anthony McCosker \\ Swinburne University of Technology \\ Andrew Dodd \\ Swinburne University of Technology
}

\begin{abstract}
Where lucrative media rights deals for sports content currently lie primarily with pay TV and free to air (FTA) broadcasters, Internet Service Providers (ISPs) entering the content delivery market through partners such as Fetch TV may be better placed to compete for distribution rights to sporting and other live events. In response to this shifting environment this paper outlines the technological capacities of NBN-based multicast Internet Protocol Television (IPTV), and examines public comment and interview data from ISPs, sports organisations and NBN Co. regarding their intentions for IPTV delivery. This paper begins with the assumption that diversity in these emerging media forms remains important as ISPs enter the media content market. We demonstrate, however, that despite the emergence of NBN-based technologies, diversity in sports content distribution cannot be assumed. The paper points toward the important role that regulators, such as the ACCC, have in maintaining diversity and competition in IPTV services.
\end{abstract}

\section{Introduction}

The design and rollout of a comprehensive fibre optic National Broadband Network (NBN) across Australia has initiated a great deal of discussion regarding innovation in both media technology and content provision.

Recent developments in the testing and pricing of wholesale multicast services by NBN Co. poses the possibility that, amongst other changes to Australia's media landscape, Internet Service Providers (ISPs) will have greater potential to deliver high definition IPTV services over the NBN. This raises the tantalising, or threatening, possibility of transformations to the distribution of premium, desirable televisual content such as sport. For sport media, where lucrative exclusive media rights deals, along with resulting sponsorship and advertising, currently lie with free to air (FTA) and subscription television, one possible outcome is that ISPs would be better placed to compete for web based and managed IPTV rights to sporting and other live events. Multicast technology made available through the NBN renders this scenario more likely. For instance, Landry Fevre, the general manager of media at NBN Co., predicts future negotiations for the rights to broadcast major Australian sports will feature 
new 'competitive tensions' by virtue of technological developments enabling new media entrants, including ISPs (Fevre 2013).

There are some important qualifications to be made here. Firstly, Australia is by no means leading the way internationally with the proposed FTTP broadband network. Secondly, a great deal hangs on the survival of the FTTP model beyond 2013, where incumbent media interests and the newly elected Coalition policy favour a lower-speed fibre to the node (FTTN) NBN that restricts IPTV capacity. In addition there is ample evidence that on the whole, the current arrangements for sports content rights and market share will become further entrenched with perhaps even greater concentration around exclusive rights deals between major sports organisations and the commercial FTA networks, and subscription television services offered primarily through Fox Sports via Foxtel. In the context of Foxtel's recent merger with Austar, Chairman of the ACCC Rod Sims, for instance, has voiced his organisation's 'ongoing disquiet' about the entrenched signing of exclusive rights in the broadcasting and online delivery of live sports (Paterson 2012). Where regulation of sports media content has been achieved primarily through 'anti-syphoning' laws managed by the Australian Communications and Media Authority (ACMA), regulatory focus would be better placed with the ACCC, in its role in maintaining diversity and competition among FTA networks, Foxtel (and Telstra) and ISPs vying for a share of the content delivery market. Sports organisations are an important part of the mix, and it is in relation to fiercely contested sports content rights that many competition concerns arise.

In light of these potential shifts, this paper examines the technological capacities of multicast and its implications for new forms of live event content delivery, and questions its ability to improve diversity in the provision of sports-related programming. We begin with the assumption that diversity in these emerging media forms remains important as ISPs enter the media content market. However, despite the development of NBN-based technologies, diversity in sports content distribution cannot be assumed. The intentions and positioning of sports organisations such as Cricket Australia (CA), as well as ISPs and the NBN Co, are instructive here. Sports organisations seem to be hedging their bets in order to maintain longstanding and profitable FTA or subscription TV partnerships, while testing new forms of online and IPTV delivery. Meanwhile, ISPs with media delivery capacity are looking for premium content to attract new customers in order to build the critical mass necessary to become significant players. Evidence so far indicates that while technological developments are bringing new players such as iiNet into the arena, they are not yet on the playing field, let alone in a competitive position to acquire major Australian sports media rights. In this context, technical developments open up the media playing field in potentia, but policy in competition regulation may be required for true innovation to happen. 


\section{Contesting sports rights in Australia}

Sport is rightly considered a prized global, national and local media commodity; however, the value really lies in the media rights - that is, in the allocation of access and the level of exclusivity provided to those who record and distribute sports media. In Australia the Australian Football League (AFL), National Rugby League (NRL) and Cricket in particular attract fierce competition between FTA broadcasters, subscription TV and online and mobile providers for exclusive media rights. This is because in a context of uncertainty, sporting events and code loyalty still ensures an audience. As Hutchins and Rowe $(2012,21)$ have pointed out: 'The value of sports rights is built upon the immediacy of fixtures'. The timelines of sports events, news and information works against time-shifting technologies and video on demand (VOD) audience preferences that affect other forms of television content.

With the rise of new technologies and platforms for delivery over the last decade, the claim has often been made that the domination of sports rights by broadcast media institutions is under threat. In a rapidly changing environment for television this is not so clear-cut (Hutchins and Rowe 2012; Cunningham and Tay 2009). Broadcasters are paying more than ever for exclusive rights, while, ironically, the fear for at least some sports organisations is that developments in convergent technologies and media industry practices will devalue sports rights (See Coalition of Major Professional Sports submission No. 31, COMPS 2009); (Paterson 2012). With the shift from protected, siloed and anti-siphoned broadcasting by a limited field of television and pay TV players to multi-screen, mobile and web based media consumption, there is a move from 'guaranteed scarcity' in sports broadcasting to 'digital plenitude' as Hutchins and Rowe put it (2008, 355-6). And in line with these shifts, it was telling that the bulk of submissions to the 2009 Senate Inquiry into Sports News and Digital Media, by media and news organisations as well as sports bodies, focused on the broad reaching implications of the changing media landscape brought about by digital and web based technologies and viewing preferences. Those with rights deals in place, such as Telstra, Foxtel, Fox Sports and the FTA channels, argued for maintenance of the status quo (See Hutchins and Rowe 2009). On the other hand, sports organisations, both through the Coalition of Major Professional Sports (COMPS) and individually, along with competing telcos such as Optus, emphasised that 'all parties have a right to share and participate in the new opportunities created by the digital landscape' (Cricket Australia submission No. 35, COMPS 2009), each in their own way experimenting with the possibilities of new technologies of content delivery.

But with lucrative exclusive rights deals still being signed, these transformations should rather be posed as a set of complex questions without clear answers. Exclusive rights deals 
continue to break records across all forms of media distribution including FTA television. For example, in April 2013, Channel Ten made a $\$ 500 \mathrm{M}$ bid to $\mathrm{CA}$ to take over exclusive rights to broadcast cricket from the current holders, Channel Nine and Fox Sports Australia (Financial Review 18 May 2013). The bid enjoyed only limited success, as Nine exercised its right to a final bid in order to retain rights to the test matches and limited-over competitions. As a sign that CA remains willing to find outlets for its varied content, Ten did acquire the rights to the Twenty2o Big Bash League domestic competition at a cost of $\$ 100 \mathrm{M}$. And Nine and Ten will share the digital rights through a $\$ 60 \mathrm{M}$ investment in Cricket Australia's existing website and development of a new mobile app (Leys and Bodey 2013). The competition between the networks ensured a total value of $\$ 590 \mathrm{M}$ - a 118 per cent increase in revenue for CA compared to previous contracts signed by Nine and Fox Sports Australia (Financial Review 5 June 2013).

In other sporting codes the price of exclusive rights deals continues to climb, and despite the changing media environment it is the traditional broadcasters that are securing exclusivity. The Seven Network broke records in the most recent round of negotiations when it paid $\$ 1.25 \mathrm{~B}$ for the right to broadcast Australian Rules football, as did Telstra by paying $\$ 153 \mathrm{M}$ for exclusive online and mobile rights (which is seen as undervalued by many analysts). Telstra's arrangements were threatened by Optus's attempt to provide 'near live' recordings and online playback through its now defunct TV Now service (Battersby 2012). Optus had offered a cloud-based service to copy and replay sports content to its customers shortly after it had been aired by rights holders such as Foxtel or FTA networks. The move, which would have seen Optus offer sports content by proxy, was blocked when the full bench of the Federal Court decided that 'time shifting' exceptions were affirmed to reside with private users, not with media providers such as Optus (See National Rugby League Investments Pty Limited $v$ Singtel Optus Pty Ltd [2012] FCAFC 59).

The uncertainty of the media rights environment in the face of changing televisual technologies and practices is significant here, and we take up on Hutchins and Rowe's point that media and sporting organisations 'are playing a "double game" of trying to maintain the profits flowing from the broadcast model of content delivery while also opening up additional, potentially profitable online channels to deliver content to sports fans' (Hutchins and Rowe 2008, 356). While sports organisations fear the devaluation of media rights, they are themselves actively seeking out new formats and distribution channels. Cricket Australia is a good example, as its 'product' - media rights to the different cricket competitions and formats - has been a driver of FTA and subscription TV profitability in Australia since the introduction of World Series Cricket by Kerry Packer's Channel Nine in the 1970 . 
CA has maintained a strong level of control over its 'digital' and online product. It has streamed footage directly on its own website since 2005, bypassing and restricting established media organisations in the online sphere (Hutchins and Rowe 2008, 362); and as noted above, CA has structured its recent digital rights deal with Channel Nine and Ten to maintain its web presence through its own website, and in the mobile space through the networks' investment in development of a new CA mobile app. Meanwhile, CA has supported the Productivity Commission in criticising the 'anti-siphoning' list in an attempt to move away from the market power of the three FTA broadcasters (Beltrame 2011, 3), presumably to free up better exclusivity deals while also retaining flexibility in terms of digital, mobile and IPTV delivery options.

The activities of CA demonstrate the complexity of exclusive rights arrangements when new technologies and modes of delivery are being tested and offered at the same time that longstanding partnerships with broadcast media are maintained. While CA representative Stephanie Beltrame sees sports fans typically gravitating to the biggest screen to watch sports events, she sees the portable and flexible nature of multi-screen options gaining greater importance (Beltrame 2011, 63.6). In Beltrame's words, 'Without question the changes in consumer behaviour, technology and convergence have and will demand changes for the way that cricket content is produced, distributed and consumed' (Beltrame 2011, 63.1). CA sees its role as navigating the technological advances and the new choices they bring fans, with the need to maintain or even grow its media rights deals with traditional outlets such as Nine.

We are interested here in the potentially disruptive outcomes of this 'double game' in terms of the specific interventions made possible by technological developments associated with the NBN.

\section{Technical interventions: Multicast and IPTV}

Late in 2012, NBN Co. began testing multicast technology within the FTTP network at a greenfields site in the Sydney suburb of Rhodes. Technical specifications were released by NBN Co. in December 2011, and the 'feature, technical and pricing' overview was published in October 2012. The official 'onboarding' process whereby service providers gain access to the multicast virtual network, began around then and a number of enthusiastic ISPs such as iiNet, TransACT, WestNet, Netspace and Internode signed up to test and eventually deliver new services. NBN Co. has promoted the Rhodes trial as the first Australian test of multicasting on optical fibre (Fevre 2013). Landry Fevre emphasises its significance for demonstrating the compatibility of the technical components of multicasting and the NBN as it has been constructed in Australia. The multicast transmission is given its own dedicated 
bandwidth, avoiding the need to compete with other broadband content. This eliminates both the buffering and low resolution of web streamed video, and importantly allows the NBN to 'guarantee the delivery of all of the package' to subscribers (Fevre 2013).

It might be telling that NBN Co.'s head of product development, Jim Hassell, describes multicast services, along with tailored business services, as the next step on the 'product roadmap' after building the consumer market for broadband and telephony over fibre, wireless and satellite (Kidman 2012). Behind essential broadband Internet services, and along with targeted business services then, multicast delivery of primarily IPTV content features as a centrepiece of the emerging (though politically vulnerable) NBN. In order to sell the NBN more generally, it seems that services that may be attractive to the general public are prioritised. This is despite the fact that in order for multicast technology to be technically and economically viable, the 'transit network' must be in place (slated for early 2015 according to NBN Co.'s website), and individual ISPs must have a critical mass of users, a scenario that may still be many years away.

Demand for web based content delivery is on the rise, and in a 2010 report the Australian Communications and Media Authority (ACMA) suggests the possibility of a shift to 'an all-IP world', where IPTV will come to dominate the commercial environment for television and video content services. IPTV can be defined to include video streamed or downloaded via the world wide web, for example through sites such as YouTube, Vimeo or ABC iView, but generally refers to Over The Top (OTT) services such as that provided by Fetch TV or subscription based entertainment services delivered through a set top box or smart TV, in partnership with Internet Service Providers, and in the form of Internet TV or Internet video services such as on-demand and catch-up TV (ACMA 2010; Kim 2009; Weinstein 2010). These are usually standard or high definition (broadcast TV or DVD quality) images in contrast to web video delivered through a browser usually at a lower image resolution. Importantly, ISPs maintain a level of management in the delivery of these services. And while YouTube has by far dominated online digital video delivery and consumption (Given, Curtis and McHutcheon 2012; Curtis, Given and McHutcheon 2012), it has been far less effective in relation to sports media due to the time critical, event oriented nature of sports.

IPTV has come to symbolise a range of possible futures for content delivery. As Pyungho Kim has elegantly argued, 'IPTV is significant because it is a new intelligent television system that symbolizes "television after TV"' (Kim 2009, 537; Spigel and Olsson 2004). As a vehicle for distributing audio-visual content, including or especially sporting events, managed IPTV services do seem to offer an attractive redress to the problematic pirated webcast and unmanaged video streaming options for sports media (Hutchins and Rowe 2008; 2012). It is through managed services over fibre to the premises connections that ISPs are able to 
provide 'true IPTV', in a media environment that connects television screens to streamed content via a closed network that apportions appropriate bandwidth and assures quality of service (Barr 2010; Cunningham 2011).

Just as important as quality of service, however, as Landry Fevre points out, is that channel usage can be logged to provide 'exact measurements of who is watching what at what time' (Fevre 2013). This in turn offers an important source of information for advertisers in relation to audience behaviours and other characteristics. Where sports bodies are finding it difficult to place a dollar value on their online and mobile rights in an emerging market place, IPTV technologies offer a better quality image than browser based options across a potentially ubiquitous, rather than piecemeal or regionally fragmented, network.

But what is FTTP multicast and what does it offer that might transform the media landscape? Multicast technology is possible through ADSL 2+ or Fibre to the Node broadband networks, but has limited application on those networks due to the variability of capacity depending on quality of the copper components or distance to a node. Even those ISPs that have maintained their own fibre or hybrid fibre-coaxial networks have limited capacity to deliver multicasting due to variable speeds or low subscriber base and these have been systematically incorporated into the NBN. Anthony Fisk of iiNet acknowledges that iiNet can only offer IP multicasting to two-thirds of its customers, namely those with either ADSL2+ or NBN fibre connections (Fisk 2013). To reach more of its DSL customer base, iiNet is also experimenting with HLS (HTTP live streaming) technology, which offers improved quality and greater manipulability (or user control over the video) over lower speed network conditions (Fisk 2013). Nonetheless, as the NBN expands its reach, the potential for IPTV and other bandwidth intensive services follows.

Multicast dedicates up to 20 Megabits per second of a 100 Mbps bandwidth to establish a managed media stream to distribute primarily, but not exclusively, quality audio-visual content. Network efficiency is gained by injecting the stream once into a network, and then replicating the data at what is called the Point of Interconnection, which is a node closer to the network termination device (NTD), of those paying ISPs for the service (see Figure 1). 


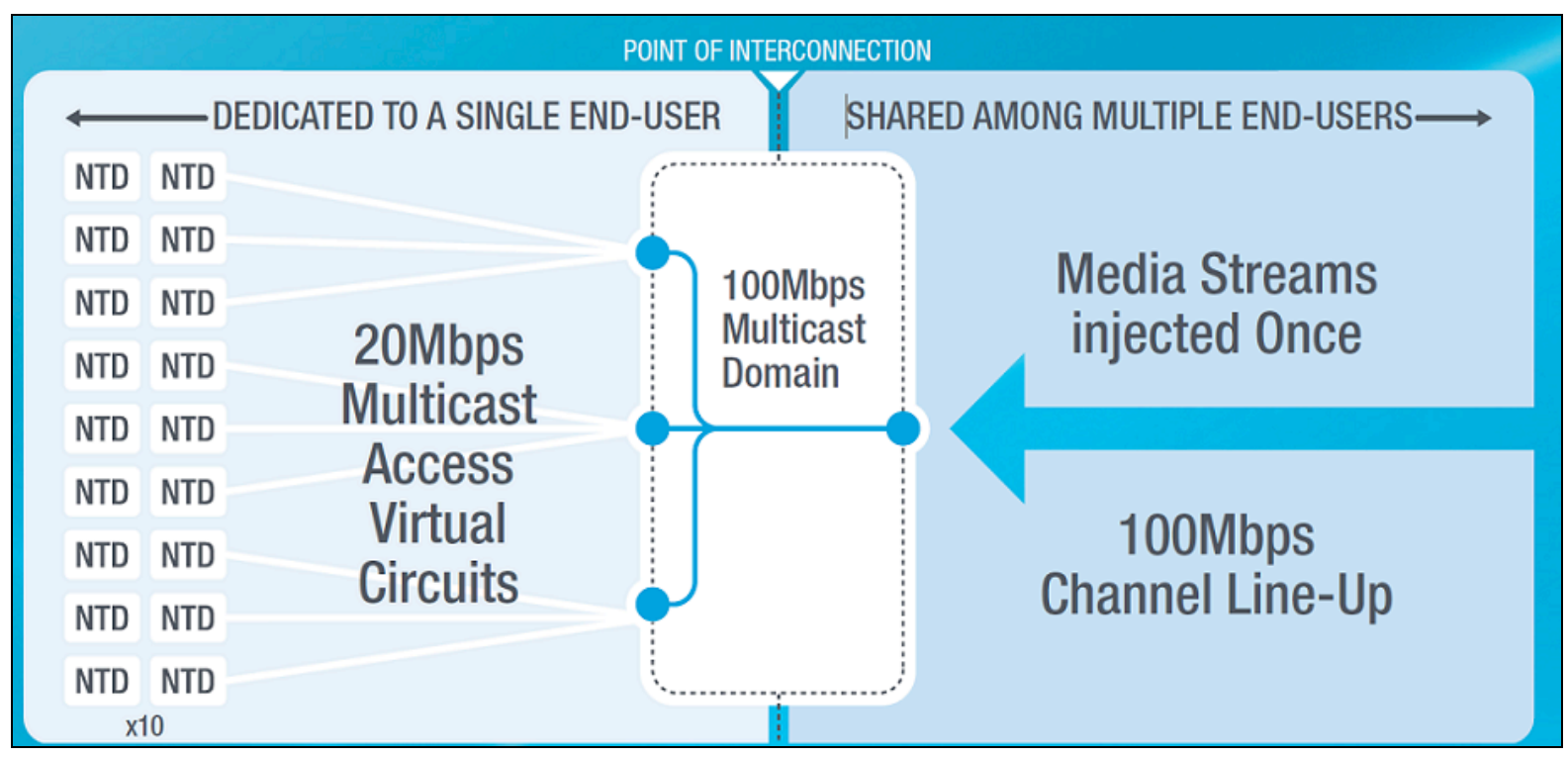

Figure 1. Multicast network design. Source: NBN Co. (2012) Fibre Access Service Multicast: Feature, Technical and Pricing Overview for Multicast over Fibre

Rather than sending bandwidth hungry standard and high definition media to each individual consumer, it is more efficiently distributed across the system, making it possible to deliver the kind of audio-visual content required for live sports for example with a reliable quality of service. One advantage here is that with the NBN in place across the country it is also easier and cheaper to establish fibre connections directly to any sporting arena or space circumventing the need for expensive broadcast facilities (Chirgwin 2013).

Fully managed, quality IPTV becomes possible once such a network is in place, and it thus becomes one of the NBN's flagship services. Consequently, NBN Co, in line with the federal department (the DBCDE), has promoted IPTV as a means to achieve an improved 'entertainment on demand' capacity. This capacity is one of the key saleable ideas underpinning the NBN, along with its capacity to facilitate 'telework' and 'telehealth,' which collectively feature within a broader policy of infrastructure developments for the emerging digital economy (nbnco.com.au.nbn-for-the-home.html).

IPTV and NBN multicast, then, operate as technological enablers for competition in platforms for media content delivery. Access to a large Internet subscriber base becomes the bedrock upon which to sell expanded IPTV entertainment packages including, or especially, sporting competitions and events. Along with the established telcos, particularly Telstra, this may involve the greater influence of ISPs such as iiNet, with the help of IPTV content service providers such as Fetch TV. But it will also rely on, we would argue, action in competition regulation to restrict exclusivity in media rights deals and the practice of 'warehousing' IPTV, web and mobile rights as a way of maintaining the dominance of FTA networks and Foxtel. These are points to which we will return below. 


\section{The rise of the ISPs? Exclusivity and competition policy}

In its submission to the 2009 Senate inquiry into the 'Reporting of Sports News and the Emergence of Digital Media', Optus highlights the shift in media consumption behaviours of its customer base, pointing out that consumers are increasingly seeking to access news and video of sport online and through mobile devices (Optus, submission No. 18, 2). Research into the uptake and use of the NBN in early stage rollout zones such as Brunswick in Melbourne have shown that 'NBN-connected homes are more likely to make greater use of the Internet, and are more likely to engage in more sophisticated online activities' (Nansen et al. 2013). In addition to expanded telework practices, the integration of the NBN into the ecology of the media home relies on both routine Internet use and 'innovative' media consumption such as that offered by IPTV delivery of entertainment and sporting competitions and events where the smart television, tablet and PC or laptop serve as an interconnected home media centre. Telcos and ISPs are positioning themselves to take advantage of shifts in consumer practices in this area (see for example Budde 2013).

This is important because it indicates the central role of what we might call either market forces or cultural practices as drivers of media industry and technology changes. Content innovation is typically worked out in practice between the desires of consumers, the designs of producers such as sports bodies and professionals, and the technical capacities available to media providers. As consumers have turned to smart TVs and wireless mobile devices linked to high speed broadband connections, ISPs have increasingly become media content providers, particularly in their ability to circumvent the need for expensive terrestrial broadcast infrastructure.

The ISPs seem best placed to deliver media content to smart TV and mobile devices, and it is assumed that they will therefore become more central in the negotiation of sports rights deals. At the very least, at stake here is a loosening of the hold that FTA and subscription TV (through the monopoly of Foxtel) has had on media content delivery, such as sports, in Australia. However, our argument here is that with the exception of Telstra as both the dominant telco and 50 per cent stakeholder in Foxtel, the second tier telcos and ISPs have entered the arena, so to speak, but are not yet on the playing field let alone competitive in negotiations for exclusive sports media rights. Interestingly, while Telstra will be careful to avoid jeopardising the value of the sports content delivered through Foxtel, it has also signalled its intent to secure digital media rights to a range of sports directly in addition to its rights to AFL games, as part of its IPTV and multi-screen strategy (Bingemann 2012).

It is also important to note, as have two key reports by the ACMA (2008; 2010), that video content services over Internet protocol is still in its embryonic stages and remains 
underdeveloped in Australia compared to other countries, notably France, South Korea, Hong Kong, Japan, Taiwan and Singapore. In those countries localised private or publicprivate high speed broadband networks have been constructed instead of a government-run national network. In addition, these countries have seen a more rapid network rollout, and more targeted IPTV services, but without the ubiquity that a national network offers. These sites have, however, demonstrated the growing significance of ISPs in terms of media content delivery, and most current estimates place the annual global revenue of IPTV at around $\$ 22$ billion, or nine to ten per cent of the subscription television revenue, with an estimated 65 million current subscribers (Broadband TV News April 2013).

In Singapore, for example, several companies have created IPTV channels to cater for a wide range of niche audiences and, through them, to build substantial subscriber numbers. Among the most prominent IPTV channels is Razor TV, which was launched by parent company Singapore Press Holdings in August 2008. Razor provides eight hours of live streaming a day, as well as video on demand. One of Razor's many channels is dedicated to local and international sport (Media Development Authority 2013). Indicative of the niche appeal of IPTV is Singapore's DeshIPTV, which caters for Bangladeshis living and working in Singapore (DeshIPTV 2013). Like many IPTV channels, DeshIPTV offers sports programming, but only in the form of re-broadcast FTA television. In South Korea, the IPTV audience has grown to six million viewers in 4 years and now comprises $25 \%$ of the country's pay-TV market. Korea Telecom has a 60\% market share, despite the presence of innovative competitors, SK Broadband and LG U+ (Dziadul 2013).

NBN Co.'s Landry Fevre notes that the changes created by the interconnections between IPTV and ISPs are happening fast, at least in Europe and Asia. He points to the 2013 French Open, where Orange held the rights to stream coverage of every match from every court, dramatically changing the nature of the coverage. However he warns that in Australia the 'competitive tensions' are less discernible because of the nature of our media market. $\mathrm{He}$ makes the point that it is in neither Telstra's nor News Limited's interests to create new IPTV channels in competition with their respective interests in Foxtel or Fox Sports. Likewise, he contends, the FTAs will work to 'protect their broadcast world as well ... because they are still in the role of protecting their audiences' (Fevre 2013).

As an emerging and successful ISP, that has aggressively pursued fibre-based Internet technologies and IPTV services through Fetch TV, iiNet's strategy offers an indicative case study here. iiNet's pursuit of ADSL 2+ and fibre network technologies and a customer base seeking the benefits of high speed broadband and data capacity has seen both rapid growth in its market share, at close to one million DSL broadband subscribers, and growing share value (McDuling 2013). In 2012, iiNet engaged in serious merger talks with similarly placed 
ISP M2 to strengthen its position in a coming media landscape where an increased scale would enable the ISPs to capitalise on the 'levelled playing field of the NBN' (McDuling 2013).

While iiNet offers two sports channels through ESPN, these do not include local sport. Without the subscriber base to support bids for media rights to local sports, iiNet will remain shut out of this form of premium content that in turn draws customers to the ISP. iiNet's spokesperson, Anthony Fisk affirms this point: 'We're at around the 15,000 - 20,000 subscriber mark, so at that level we're not in a position to be actively bidding for some of the high profile sports. As we expand we may be in more of a position to do so' (Fisk 2013). More significantly, however, Fisk also notes the ISP's future is tied to attracting a subscriber base through IPTV services in partnership with Fetch TV: 'We believe that the future is that more and more people will get on board with Fetch and then we're in a position to do that' (Fisk 2013). Fisk says Fetch TV is well placed to attract market share as an IPTV content provider that partners with multiple ISPs in Australia such as iiNet, Optus, Adam Internet and Internode. He contends that this arrangement strengthens Fetch TV's ability to secure rights for cinema, television content, music and sports content and allows flexibility for customers who want to shift providers. And yet, while iiNet and other ISPs have been able to use platforms like Fetch TV to introduce IPTV offerings and build subscriber bases, it has been predominantly through non-exclusive overseas content.

ISPs such as iiNet face the prospect of viable IPTV service delivery at a scale that indicates a potentially stable profit stream, a prospect that is greatly enhanced by (but not solely dependent upon) the rollout of a national FTTP network. However, the major consideration, or roadblock, to this scenario, revolves around the sequestering of precious premium content such as Australian sports media rights. As Paul Patterson notes, exclusive rights to premium media content has been identified by both the Convergence Review Report (DBCDE 2012) and the Australian Competition Consumer Commission (ACCC) as 'potentially powerful impediments to competition in the rapidly converging telecommunications and media sectors' (Patterson 2012, 45.1).

Patterson argues that 'recent developments in audio-visual content supply, demand and distribution ... have the potential to strengthen competition in the market for premium audio-visual content' (Patterson 2012, 45.2). While Patterson is able to point to evidence of this in other areas of entertainment content, we disagree with his arguments in relation to sports media rights. The developments he points to for sports content - fragmentation of rights, time-shifting, direct supply to consumers by content producers - have not yet loosened the hold of FTA and pay TV on sports content delivery. For example, as noted above, CA has fragmented the rights for different cricket formats only very minimally 
(granting rights to domestic Twenty2o cricket to Channel Ten). Similarly, Optus's failed attempt to offer a TV Now record and play service demonstrates the lengths sports bodies and media rights holders will go to protect the exclusivity of their intellectual property rights to broadcast sporting events. And while the supply of IPTV content directly to consumers by sports organisations has some precedent overseas, particularly for large sporting clubs such as Manchester United Football Club, there is no indication yet that this is viable for the much smaller Australian market or will operate outside of the established providers such as Foxtel.

Sections 45, 46 and 47 of the Competition and Consumer Act 2010 (Cth) recognise the potential anti-competitive behaviour arising from exclusive contracts, and Part 3 of the DBCDE's Convergence Review (2012) deals extensively with this issue. The authors of the Convergence Review note:

Access to premium content, such as first-release movies and live sport, can be vital to ensure the success of media platforms, including new and emerging platforms. Innovation, competition and positive consumer outcomes may be threatened where exclusive content rights prevent such access. (DBCDE 2012, 30)

In addition to the powers of the ACCC as they were further refined through the Competition and Consumer Act 2010 (Cth), the Convergence Review recommends establishing a communications regulator with powers to address content-based competition issues. The latter scenario seems unlikely; however, as Paterson notes, the ACCC has enforced restrictions to exclusivity deals for movie and television content in Foxtel's merger deal with Austar (2012, 45.1). It has become increasingly clear that developments in new media delivery technologies and changes to viewing preferences shifts the emphasis in sports content regulation away from the ACMA managed anti-syphoning laws, toward competition regulation for service providers. This is the broader recommendation of the Convergence Review, if not the political will of the newly elected Liberal National Party.

The Competitive Carriers' Coalition (CCC), representing telcos and ISPs other than Telstra (with its ongoing market dominance), advocates for further regulatory action to prevent what it sees as the inevitably monopolistic influence that can be exerted through the acquisition of exclusive content deals (Minehane and Molloy 2012). They also single out exclusive rights to sports as the key vehicle for such anti-competitive activity, and recommend that a specific regulatory framework be promulgated to deal with content access issues in addition to the powers granted to the ACCC under the Competition and Consumer Act 2010 (Cth), that is, beyond the point of acquisitions and mergers. This may have some merit, as well as unforeseen consequences. On the evidence to date we argue that continued 
monitoring of exclusive rights deals will be necessary as Australia's telecommunications and televisual environment opens up through new technologies such as NBN multicast and IPTV.

\section{Conclusion}

Although we are witnessing exciting technological developments in emerging FTTP networks and multicast IPTV delivery, we contend that greater diversity of content providers on the media playing field, and greater involvement by emerging ISPs and telcos, remains in potentia only. It remains to be seen what effects a shift to a fibre to the node and VDSL NBN model will bring to IPTV services. Tests on the FTTP network show that multicast is, technically speaking, stable, consistent and efficient, offering a quality of service and media monitoring capacity that could easily open up new business models for content production and distribution in Australia. However, it is politically and commercially vulnerable. It can offer a higher quality alternative to online, browser-based streaming services such as YouTube, or illegal peer-to-peer file sharing through bit torrent sites. What is less certain or stable, is the positioning of content creators such as sporting bodies and the barriers to content access erected by powerful media players.

The cases of Cricket Australia and iiNet have been instructive. Where CA seeks to both maintain its exclusive rights deals with traditional broadcast partners, it is also looking to the potential of online and multiscreen options for new forms of delivery. ISPs are likewise looking to innovate in this area. As with other ISPs capitalising on convergent technologies and consumer practices, iiNet has grown at a staggering rate and now operates as a significant media delivery organisation through Fetch TV. With this in mind, perhaps both diversity and innovation are best served by re-examining the policy frameworks and the mechanisms for addressing what have been described as the competition roadblocks posed by long-term exclusive sports media rights deals, as advocated by the CCC. Whether the ACCC's power under the Competition and Consumer Act 2010 (Cth) is adequate to manage growth and innovation in this sector remains to be seen, and is already made problematical by its reluctance to curb Foxtel's exclusive sports rights deal in its approval of a merger with Austar.

Further work can be done in monitoring such drivers of media transformations around key content forms and delivery modes. The aim of our broader project, of which this is a more exploratory, scoping phase, is to consider how specific forms of media content and communication practices are helping to shape the use of high speed broadband, and how these are driving the development of broadband applications and market structures from the panoply of possibilities on offer. 


\section{References}

ACMA. 2008. IPTV and Internet video services: The IPTV and Internet video market in Australia. Canberra: ACMA.

ACMA. 2010. IPTV and Internet video delivery models: Video content services over IP in Australia. Canberra: ACMA.

Barr, Trevor. 2010. 'A Broadband Services Typology'. The Australian Economic Review 43 (2), 187-193. http://doi.org/10.1111/j.1467-8462.2010.00592.x

Battersby, Lucy. 2012. 'Optus to Shut Down TV Now After Losing Appeal'. Sydney Morning Herald (7 September). Accessed 14 May 2013. Available from:

http://www.smh.com.au/business/optus-to-shut-down-tv-now-after-losing-appeal20120907-25ijm.html

Beltrame, Stephanie. 2011. 'The New World of Selling Content: Cricket as a Case Study'. Telecommunications Journal of Australia 61 (4), 63.1-63.7.

http://doi.org/10.7790/tja.v61i4.256

Bingemann, Mitchell. 2012. 'Telstra Targets Sports Rights'. The Australian (3 December). Accessed 22 May 2013. Available from:

http://www.theaustralian.com.au/media/digital/telstra-targets-sports-rights/storyfnao3wxu-1226528453528

Broadband TV News. 2013. 'Over 100m IPTV Homes by 2017'. (25 April). Accessed 27 April 2013. Available from: http://www.broadbandtvnews.com/2013/04/25/over-100miptv-homes-by-2017/

Budde, Paul. 2013. Australia, Digital Media, IPTV, Major Players. Accessed 10 July 2013. Available from: http://www.budde.com.au/Research/Australia-Digital-Media-IPTVMajor-Players.html

Chirgwin, Richard. 2013. 'NBN Multicast: Australia's TV Distribution Revolution'. $A B C$ Technology and Games, (11 February). Accessed 20 February. Available from: http://www.abc.net.au/technology/articles/2013/o2/11/3687398.htm

COMPS (Coalition of Major Professional Sports). 2009. Submission to 'Inquiry into the Reporting of Sports News and the Emergence of Digital Media'. Senate Standing Committee on Environment, Communications and the Arts. Canberra: Parliament of Australia.

Cunningham, Stuart. 2011. 'Broadband, the NBN and Screen Futures'. Media International Australia 140 (August), 16-21.

Cunningham, Stuart; Tay, Jinna (eds). 2009. Television Studies After TV: Understanding Television in the Post-Broadcast Era, Hoboken, Taylor and Francis.

Curtis, Rosemary; Given, Jock; McCutcheon, Marion. 2012. Online Video in Australia: Exploring Audiovisual Fiction Sites. The Swinburne Institute, Swinburne University of Technology. Accessed 12 January 2013. Available from:

http://researchbank.swinburne.edu.au/vital/access/manager/Repository/swin:2662 Z

DBCDE. 2012. Convergence Review: Final Report. Canberra: Commonwealth of Australia.

DeshIPTV. Accessed 3 July 2013. Available from: http://www.deshiptv.com/aboutus.php

Dziadul, Chris. 2013. 'IPTV surges in Korea' TV Connect, published in Broadband TV News, 20 March 2013 http://www.broadbandtvnews.com/2013/03/20/iptv-surges-inkorea/ 
Fevre, Landry. 2013. NBNCo, General Manager, Media. Interview with co-author, June 2013.

Fisk, Anthony. 2013. iiNet, interview with co-author, June 2013.

Financial Review. 2013. 'TV Cricket Rights: Nine Ponders a Declaration'. (18 May) Accessed 20 May 2013. Available from:

http://www.afr.com/p/business/marketing_media/tv_cricket_rights_nine_ponders _declaration_YwGXJhXBToLT32neW6VrPJ

Given, Jock; Curtis, Rosemary; McCutcheon, Marion. 2012. 'Online Video in Australia'. International Journal of Digital Television 3 (2), 141-162. http://doi.org/10.1386/jdtv.3.2.141_1

Hutchins, Brett; Rowe, David. 2008. 'From Broadcast Scarcity to Digital Plenitude: The Changing Dynamic of the Media Sport Content Economy'. Television and New Media 10 (4), 354-370. http://doi.org/10.1177/1527476409334016

Hutchins, Brett; Rowe, David. 2009. “A Battle Between Enraged Bulls”: The 2009 Australian Senate Inquiry into Sports News and Digital Media'. Record of the Communications Policy and Research Forum. Accessed 30 July 2010. Available from:

http://www.uws.edu.au/__data/assets/pdf_file/ooo6/138174/HutchinsRowe_Battl eBetweenEnragedBulls.pdf

Hutchins, Brett;, Rowe, David. 2012. Sport Beyond Television: The Internet, Digital Media and the Rise of Networked Media Sport. Routledge: New York.

Kidman, Angus. 2012. 'How Multicast will Improve NBN Video Services'. Lifehacker (28 September). Accessed 4 November 2012. Available from:

http://www.lifehacker.com.au/2012/o9/how-multicast-will-improve-nbn-videoservices/

Kim, Pyungho. 2009. 'Internet Protocol TV in Perspective: A Matrix of Continuity and Innovation'. Television and New Media 10 (6), 536-545.

http://doi.org/10.1177/1527476409340908

Leys, Nick; Bodey, Michael. 2013. 'Cricket Wins with Split Deal on Television Rights' The Australian, (4 June). Accessed 7 June 2013. Available from:

http://www.theaustralian.com.au/media/ten-splits-cricket-with-nine-in-550mdeal/story-e6frg996-1226656393483

McDuling, John. 2013. 'iiNet, M2 considered merger in face of impending NBN', Financial Review (22 April). Accessed 22 April 2013. Available from:

http://www.afr.com/p/technology/iinet_considered_merger_in_face_hgeTTlAarGY wkSGpXyNZzL

Media Development Authority, Singapore. Accessed 2 July 2013. Available from: http://www.mda.gov.sg/POLICIES/POLICIESANDCONTENTGUIDELINES/TV/Pa ges/IPTV.aspx

Minehane, Scott; Molloy, Simon. 2012. Exploring Content-Related Competition Issues: Will Exclusive Rights be the New Bottleneck in the Australian Telecommunications Sector? Paper for the Competitive Carriers' Coalition, Windsor Place Consulting. Accessed 22 January 2013. Available from:

https://www.dropbox.com/s/wqa3yflx2uiti7l/CCC\%20Content\%20Access\%20Repor t\%2013\%20Nov\%202012.pdf

Nansen, Bjorn; Arnold, Mike; Wilken, Rowan; Gibbs, Martin. 2013. Broadbanding Brunswick: High-speed Broadband and Household Media Ecologies: A Report on Household Take-up and Adoption of the National Broadband Network in a First Release Site, Australian Communications Consumer Action Network, Sydney. 
NBN Co. 2012. Fibre Access Service Multicast: Feature, Technical and Pricing Overview for Multicast over Fibre. Accessed 22 July 2013. Available from:

http://www.nbnco.com.au/industry/service-providers/product-

components/multicast.html

OPTUS. 2009. Submission to 'Inquiry into the Reporting of Sports News and the Emergence of Digital Media'. Senate Standing Committee on Environment, Communications and the Arts. Canberra: Parliament of Australia.

Paterson, Paul. 2012. 'Is Access to Content Really the New Bottleneck?'. Telecommunications Journal of Australia 62 (3), 45.1-45.11.

http://doi.org/10.7790/tja.v62i3.341

Razor TV. Accessed 3 July 2013. Available from: http://www.razor.tv/site/servlet/segment/main/about/

Spigel, Lynn; Olsson, Jan (eds). 2004. Television after TV: Essays on a Medium in Transition. Duke University Press, Durham, North Carolina.

Weinstein, Jeremy. 2010. 'NBN and IPTV: Rich Potential'. Telecommunications Journal of Australia, 60 (2), 23.1-23.9. http://doi.org/10.2104/tja10023

Cite this article as: McCosker, Anthony; Dodd, Andrew. 2013. 'The future of sports delivery in Australia. NBN multicast, IPTV and the role of the ISPs'. Australian Journal of Telecommunications and the Digital Economy 1 (1): pp.3.1 - 3.16. DOI: $10.7790 /$ ajtde.v1n1.3 Available at: http://telsoc.org/journal 